\title{
ReSEARChArticle
}

\section{Assessment of antifungal activity of phytoextracts on Fusarium wilt of lentil}

\author{
Pawan L. Deshmukh and Umesh P. Mogle
}

\section{SUMMARY}

The cultivation of pulses has been practiced from thousands of years. Ancient civilizations in Mesopotamia grew peas, beans and lentils as far back as $8000 \mathrm{BC}$. India is one of the second largest lentil producers in the world after Canada. In South Asian cuisine, split lentils are known asDal,the lentil is a dietary staple throughout regions of India and other developing countries in Asia. Majority of the production of lentil comes from Canada, India and Australia from total world production. These staple crops have been an integral part of human diets for millennia and today are an important crop not only for food security, but also for combating malnutrition, improving human health, alleviating poverty and enhancing agricultural sustainability. However, yield of lentil remains low due to biotic and abiotic stresses. One of the major biotic stress comes from Fusarium wilt (Fusarium oxysporum f.sp. lentis) affect lentil and cause severe yield loss. In order to overcome biotic stress caused by Fusarium species eco-friendly biological methods has to be discovered in order to avoid the huge loss due to such biotic stress. This study mainly focused on the development of biological methods to combat against these biotic stresses in environmental friendly manner.

Key Words : Antifungal, Fusarium oxysporum, Pulses, Biotic stresses

How to cite this article : Deshmukh, Pawan L. and Mogle, Umesh P. (2019). Assessment of antifungal activity of phytoextracts on Fusarium wilt of lentil. Internat. J. Plant Sci., 14 (1): 19-24, DOI: 10.15740/HAS/IJPS/14.1/19-24, Copyright@ 2019: Hind AgriHorticultural Society.

Article chronicle : Received : 22.10.2018; Revised : 05.12.2018; Accepted : 14.12.2018

\section{MEMBERS OF THE RESEARCH FORUM}

Author to be contacted :

Pawan L. Deshmukh, Department of Botany, J. E. S., R. G. Bagdia

Arts, S.B. Lakhotia Commerce and R. Benzonji Science College, Jalna

(M.S.) India

Email : pawandeshmukh5@gmail.com

Address of the Co-authors:

Umesh P. Mogle, Department of Botany, J. E. S., R. G. Bagdia Arts, S.B. Lakhotia Commerce and R. Benzonji Science College, Jalna (M.S.) India

Email : upmogle@gmail.com 